\title{
Reflexões sobre a territorialidade Kaingang e a importância da inter-trans-disciplinaridade
}

\author{
Kimiye Tommasino*
}

TOMMASINO, K. Reflexões sobre a territorialidade Kaingang e a importância da intertrans-disciplinaridade. R. Museu Arq. Etn., 27: 121-134, 2016.

Resumo: Este artigo tem como objetivo - a partir de muitas experiências de pesquisa e extensão com os Kaingang ${ }^{1}$ - tecer algumas considerações sobre as limitações do paradigma cartesiano que ainda impera nas universidades e mostrar que uma das formas de superá-las é adotar abordagens inter-trans-disciplinares. Tento demonstrar que esse recurso permite avançar nas análises sobre a complexificação das realidades vividas pelos Kaingang ao longo da história recente. Para isso recorto como exemplo as pesquisas sobre territórios e territorialidades kaingang no Paraná e em Santa Catarina. Por fim, tento mostrar que existem ainda aspectos importantes da realidade sociocultural e histórica desse povo que não têm sido tema de pesquisas específicas.

Palavras-chave: Kaingang; Interdisciplinaridade; Antropologia; Territorialidade

\section{Características da produção científica}

O pensador francês Edgar Morin tem sido uma referência nesses últimos 20 anos porque não apenas fez a crítica à fragmentação do conhecimento científico como também elaborou, a pedido do governo francês, uma proposta de reforma do sistema educacional nos níveis fundamental, médio e superior. Morin afirma que

"Apesar de estar englobada num conjunto científico mais vasto, uma disciplina tende naturalmente à autonomia pela delimitação de suas fronteiras, pela linguagem que instaura, pelas técnicas que é levada a elaborar ou a utilizar e, eventualmente, pelas teorias que lhes são próprias, como atestam os exemplos da

1 Minhas pesquisas se distribuíram entre 1986/87 até praticamente 2007 e meus projetos de extensão à comunidade seguiram paralelamente e, desde o início, incluíram os Kaingang, Guarani e Xetá.

(*) Professora aposentada da Universidade Estadual de Londrina-UEL. Doutora em Antropologia Social pela FFLCH-USP. <kimiye13@gmail.com> biologia molecular, da ciência econômica ou da astrofísica" (Morin 2002: 37).

A organização disciplinar foi instituída no século XIX "principalmente com a formação das universidades modernas e, depois, desenvolveu-se no século XX, com o progresso da pesquisa científica (Morin 2002: 37). Apesar da fecundidade da disciplinaridade, Morin (2002: 38) salienta que

"a instituição disciplinar acarreta, simultaneamente, um risco de hiperespecialização do investigador e um risco de "coisificação" do objeto estudado, percebido como uma coisa em si, correndo-se o risco de esquecer que o objeto é extraído ou construido. As ligações e solidariedades deste objeto com outros objetos tratados por outras disciplinas passam a ser negligenciadas, assim como as ligações e solidariedades deste objeto com o universo do qual faz parte. A fronteira disciplinar, com sua linguagem e com os conceitos que lhe são próprios, isola a disciplina em relação às outras e em relação aos problemas que ultrapassam as disciplinas. Desse modo, o espírito hiperdisciplinar corre o risco de se consolidar, como o espirito de um proprietário 
que proíbe qualquer circulação estranha na sua parcela de saber".

Mas como bem lembra o autor, a história da ciência registra também a

"ruptura de fronteiras disciplinares, de sobreposições de problemas de uma disciplina sobre a outra, de circulação de conceitos, de formação de disciplinas híbridas que terminaram por se autonomizar. É, igualmente, a história da formação de complexos nos quais diferentes disciplinas se agregam e se aglutinam. Dito de outra forma, se a história oficial da ciência é a da disciplinaridade, a 'inter-trans-poli-disciplinaridade', embora ligada e inseparável dela, constitui uma outra história, que lhe é associada e inseparável" (Morin 2002: 40).

Esse processo ocorreu nas fronteiras entre a Física, a Química e a Biologia que produziu a chamada revolução biológica ocorrida nos anos 1950, na História em cujas margens se abriu para a Economia e à Sociologia e mais tarde, à Antropologia que se materializa nos trabalho de Georges Duby e Jacques Le Goff sobre a Idade Média. Ocorreu também na Pré-História (Arqueologia) que, a partir das descobertas de Louis Leakey passou a agrupar cientistas de várias disciplinas e a exigir cada vez mais a policompetência do pesquisador, pois que o objeto de estudo passou a "ser a hominização, processo não só anatômico e técnico, mas também ecológico, genético, etológico, psicológico, sociológico, mitológico" (Morin 2002: 42-43).

Com relação ao processo em questão envolvendo a Antropologia, Morin lembra que,

Mais importantes ainda são as transferências de esquemas cognitivos de uma disciplina à outra. Claude Lévi-Strauss não teria podido elaborar sua antropologia estrutural se não tivesse encontrado Jakobson em Nova Iorque, nos bares ao que parece. Jakobson já havia elaborado a linguística estrutural e os dois não se teriam reencontrado se não fossem ambos refugiados da Europa. Jakobson fugira alguns decênios antes da Revolução Russa, Lévi-Strauss deixara a França ocupada pelos nazistas (Morin 2002: 41).
Morin vai mostrando, através de alguns exemplos rápidos sobre a variedade de circunstâncias que permitiram romper o isolamento das disciplinas promovendo a migração de conceitos e a hibridização em novos campos, as transferências de esquemas cognitivos de uma disciplina a outra e outros processos que deram surgimento a objetos simultaneamente inter-poli-transdisciplinares.

O Brasil não foge à regra, os cursos são atomizados em disciplinas; as disciplinas são setorizadas em departamentos, algumas vezes separados em centros diferentes e distantes entre si. Isso significa que muitas vezes um departamento e/ou centro desconhece as pesquisas que são realizadas dentro da mesma universidade. Isso afeta o produto porque não há troca de experiências e muito menos integração dos conhecimentos produzidos. O paradigma cartesiano predomina nas universidades brasileiras e apresenta as limitações e problemas apontados por Morin.

Tendo apresentado o quadro onde se produz o conhecimento científico, faremos nos próximos tópicos, um apanhado sobre as experiências de pesquisa com os Kaingang, mostrando tanto as limitações oriundas da disciplinaridade quanto os avanços conseguidos, principalmente ao incorporar análises inter-trans-disciplinares .

\section{Brevíssimo balanço da produção sobre os Jê do Sul}

Os Kaingang foram objeto de estudo etnográfico e etnológico na primeira metade do século XX, por Nimuendaju (1993 [1913]), Baldus (1979 [1937]) e Schaden (1959). Esses estudos são preciosos e nos permitem compreender os complexos processos de mudança cultural após o contato com os fóg (brancos) e suas agências civilizatórias. Nimuendaju e Baldus trabalharam como indigenistas do SPI e tiveram o privilégio de conviver de perto com vários grupos kaingang quando algumas de suas instituições sociais "tradicionais" eram operativas. Adotando um conceito de cultura como produto acabado e adeptos da teoria da aculturação, todos eles vislumbravam o iminente desaparecimento da 
cultura kaingang. No entanto, deixaram importantes registros sobre seus sistemas de representação do mundo, organização social, mitos e ritos. Esses estudos têm fornecido subsídios importantes aos pesquisadores atuais preocupados em compreender a realidade desse povo do ponto de vista êmico e ético, no presente etnográfico.

Os Kaingang já foram considerados "integrados" e "camponeses" em estudos de cunho sociológico desde os anos de 1960 até quase toda a década de 1980. Os Kaingang e os Xokleng foram estudados dentro do projeto "Estudos de Áreas de Fricção Interétnica no Brasil" patrocinado pelo Centro Latino-americano de Pesquisas em Ciências Sociais. Esses estudos denunciaram as formas de conquista, dominação e exploração das sociedades indígenas pelo sistema capitalista, legitimado pelo Estado e suas políticas indigenistas. Essa corrente predominou nos estudos sobre os índios da região sul porque as populações indígenas já se encontravam economicamente inseridas no mercado regional e o foco das análises eram os sistemas de fricção interétnica e suas consequências. Esses olhares "de fora e de cima”, imprimiram imagens de populações indígenas indiferenciadas em relação à população rural nacional, ofuscando, de certa forma, a reflexão sobre a sociedade kaingang.

As décadas de 1980 e 90 trouxeram novas contribuições teóricas e conceituais que permitiram repensar as análises sobre mudança sociocultural, conferindo resultados mais satisfatórios e refinados. Na base dessas novas abordagens e teorias, apesar das diferenças entre elas, o conceito de cultura aparece renovado, reavaliado e reformulado, agora como processo permanente de criação e recriação de significados. Ao superar o conceito estático de cultura, a imagem de povos indígenas como sociedades evanescentes e em fase terminal também foi revista (Tommasino 1995). Essas contribuições permitiram uma revisão das análises e das interpretações dos dados das pesquisas de campo sobre os Kaingang a partir de 1990 .

Desde então, várias pesquisas etnográficas foram realizadas com os Kaingang no Paraná, Santa Catarina e Rio Grande do Sul, tendo em comum a apresentação da história e da cultura do ponto de vista dos nativos. Pode-se dizer que essas novas pesquisas resultaram em verdadeiras descobertas sobre as especificidades socioculturais dos Kaingang contemporâneos, revelando que o pensamento kaingang, mesmo tendo sofrido profundas alterações na forma e no conteúdo continua seguindo seus próprios princípios lógicos. A teoria da aculturação é que padecia de insuficiências e não dispunha de suporte teórico, conceitual e metodológico para apreender os processos na sua internalidade, isto é, na dinâmica interna, interpretando as mudanças culturais como processos permanentes de (re)significação simbólica e prática dos elementos estrangeiros incorporados pela situação de contato ou de criação original de elementos fundamentais para a reprodução da coletividade (socialidade) e materialidade (sobrevivência física) .

Os anos 1990 podem ser tomados como marcos da retomada dos estudos etnográficos e etnológicos sobre os Kaingang. Daquele período até os dias atuais temos uma significativa e diversificada produção sobre organização social e parentesco, ritual e xamanismo, organização política, sistemas de saúde e políticas de saúde, sistema de educação e políticas de educação, religião e religiosidade, etnobotânica, etno-história e etno-arqueologia, território e territorialidade, ecologia, identidade étnica, construção do corpo e corporalidade. Essa produção revela a integração de áreas diversas de conhecimento com a antropologia e a etnologia e essas contribuições mostram que houve uma circulação de conceitos que permitiram enriquecimentos mútuos.

Naturalmente, essa renovação se deu também nos estudos de outros povos indígenas em todo o território nacional. $\mathrm{O}$ cenário político nacional, com a promulgação da CF em 1988 e as novas conquistas indígenas, registrou grandes avanços na luta desses povos pelos direitos conquistados. Não por caso, esse período registra várias demandas indígenas na região sul - dos Kaingang, Xokleng, Guarani e Xetá - que envolveram, direta e/ou indiretamente, a participação de vários antropólogos. Essas demandas acabaram por incrementar mais pesquisas sobre os índios do Sul, abrindo caminho para novos estudos para elaboração de laudos e perícias de terras indígenas, de conflitos variados envolvendo indígenas, de identidade étnica, de estudos 
Reflexões sobre a territorialidade Kaingang e a importância da inter-trans-disciplinaridade

R. Museu Arq. Etn., 27: 121-134, 2016

de impactos de grandes obras (rodovias e UHEs) em comunidades indígenas.

As novas pesquisas sobre os Kaingang, como vimos, puderam se beneficiar das discussões teóricas que romperam as dicotomias criadas pelas escolas clássicas e modernas. Pode-se dizer que as antigas correntes do pensamento antropológico saíram de seus casulos e passaram a trocar experiências e a integrar conhecimentos assim como a repensar conceitos, ou mesmo criar novos conceitos, mais refinados e mais instrumentais para interpretar os processos sociais.

\section{A inter e a transdisciplinaridade como formas de romper as dicotomias}

Foi nesse momento e nesse ambiente que se formou o GT Estudos Interdisciplinares dos Jê do Sul, reunindo antropólogos, arqueólogos, historiadores, linguistas e profissionais de várias áreas (medicina, farmácia, biologia, etc.) voltados para as pesquisas dos Kaingang e dos Xokleng. Podemos dizer que as discussões do GT nas Reuniões do Mercosul-RAM mostraram o quanto a troca de experiências entre profissionais de várias áreas do conhecimento foi enriquecedora para todos os envolvidos. Houve uma grande circulação de conhecimentos e todos saíram beneficiados; a rede continua funcionando entre colegas de diferentes instituições - todos trabalhando em colaboração mútua e somando experiências. Esse conjunto de pesquisas resultou em beneficio aos povos indígenas que podem contar com dados sobre arqueología, história e cultura kaingang para subsidiar suas lutas atuais por terras perdidas e por reparação de danos ambientais e sociais. São importantes também para elaboração das justificativas de seus projetos de educação escolar indígena, de gestão de suas terras e políticas de saúde, entre outros.

A renovação teórica e conceitual foi acompanhada dessa união de pesquisadores de áreas diversas que implantaram a inter-trans-disciplinaridade. A integração de métodos, teorias e conceitos entre Antropologia, Arqueologia/ História, Biologia/Botânica, Ciências da Saúde, etc., mostrou rendimentos incrivelmente altos nas experiências ocorridas, por exemplo, entre os pesquisadores dos cursos de pós-graduação sob a orientação da Professora Jean Langdon na UFSC. Outro exemplo de integração entre Arqueologia, História e Antropologia é a UFRGS e, ao que parece, se trata de uma tradição antiga naquela instituição.

No Paraná também temos participado de experiências dessa natureza: 1) na UEL, desde o início, minhas pesquisas buscaram apreender a história dos povos indígenas na sua diversidade étnica, integrando-os dentro do panorama histórico de conquista e ocupação de seus territórios nas bacias do Tibagi, Laranjinha e Cinzas; tais estudos tiveram como preocupação mostrar os aspectos tanto macro quanto micro-sociológicos; 2) na UEM, através do Programa Interdisciplinar de Estudos de Populações/Laboratório de Arqueologia, Etnologia e Etno-História (LAEE) coordenado por Lúcio Tadeu Mota e de cuja equipe de pesquisa Chico Noelli e eu fizemos parte desde 1994. Das experiências acumuladas, surgiram inúmeras publicações entre as quais aponto o livro "Os Kaingang do Vale do IvaíPR: história e relações interculturais” de Lúcio Tadeu Mota e Éder da Silva Novak (2008), como expressiva das questões aqui abordadas. Nesse livro, Mota e Novak adotam a perspectiva inter-trans-disciplinar mostrando a presença das populações indígenas desde a pré-história e como se deu a conquista e a desterritorialização dos Kaingang na bacia do Ivaí ao longo dos séculos até a atual configuração das TIs.

As pesquisas que adotaram estas abordagens conseguiram mostrar os processos de mudança sociocultural e territorial do ponto de vista dos indígenas, a partir do cruzamento dos dados arqueológicos, históricos e etnográficos onde os processos culturais passaram a ser estudadas na sua dinâmica interna e externa de complexificação e transformação, buscando apreender os significados das ações pragmáticas e das performances dos atores sociais em confronto. Aqueles mesmos sistemas antes considerados indicadores de aculturação e perda cultural, foram reinterpretados agora como formas contemporâneas, criadas e ressignificadas pelos Kaingang. Nestes novos estudos, os Kaingang aparecem como sujeitos da história e não reificados na condição de vítimas dela. 
Quero ainda falar sobre a importância dos estudos da Linguística, principalmente da Linguística Histórica e Sociolinguística, como importante aliada de nossas pesquisas. Pessoalmente me beneficiei de alguns dados das análises comparativas dos dialetos kaingang e das línguas kaingang e xokleng feitas pela linguista Ursula Wiesemann $(1967,1978)$. Pela importância desses trabalhos que nunca foram publicados, mas apenas divulgados para um público restrito, registro duas delas que podem interessar tanto aos etnoarqueólogos quanto aos etnólogos e historiadores. Ao estudar a incorporação da palavra Topẽ, Wiesemann (1987: 212) diz que

"Um estudo de palavras emprestadas e o grau de assimilação delas à língua Kaingáng poderia elucidar o contato dos grupos entre si. Uma palavra de interesse especial é o empréstimo do Guarani Topẽ 'Deus' - tupã em Guarani. No primeiro vocabulário publicado, de A. Saint-Hilaire de 1820, topẽ já ocorre, e esta palavra se acha em todos os vocabulários subsequentes. Em 1626-27 um primeiro contato com os "Gualachos" foi estabelecido pelo Pe. A. Ruiz de Montoya, com a ajuda de um Guarani que tinha aprendido a língua Kaingang quando se acidentou numa visita àquele grupo. Ele serviu de intérprete para os primeiros padres, e é bem provável que Topẽ foi introduzido por ele. Infelizmente não temos muito material linguístico daquele tempo - vocabulário, gramática e catecismo, elaborados pelos dirigentes da "Reducción de la Concepción de los Gualachos' foram perdidos. Em SP [referindo se ao dialeto de SP] e em $\chi$ [referindo se à língua Xokleng], esta palavra é desconhecida. Em SP se usa kankẽ 'céu' para Deus, sem fazer diferença entre o céu e aquele que criou os céus. Em X usam-se expressões como kõñka-tã-nê-ti 'aquele que está no céu'”.

Sobre a distância/diferença entre os dialetos SP e demais, Wiesemann (1987: 215), diz:

"SP tem menos em comum com os outros dialetos do que estes entre si, indicando que este grupo se separou dos outros algum tempo depois da separação entre K [Kaingang] e X. Se de fato Topẽ foi introduzido em 1626, SP e X não tinham mais contato com os outros grupos depois deste acontecimento, visto que lá não se conhece esta palaura".

Outro dado que foi importante para a minha pesquisa relaciona-se ao território kaingang e a forma como se expandiram por fissão política e separação geográfica. A hipótese da linguista é que,

"Depois de se separarem dos outros grupos Jê, os indios Kaingáng começaram a sua migração para o sul. O primeiro grupo a se separar foram os Xokléng que emigraram até Santa Catarina e não tinham mais contato amigável com os outros grupos. Uma segunda separação aconteceu entre o grupo SP e os outros Kaingáng - os últimos continuaram sua migração para o sul. Passado o rio Paranapanema não havia mais contato"(Wiesemann 1987: 216).

Justamente essa hipótese levantada por Wiesemann me ajudou a elaborar a interpretação sobre as experiências históricas dos grupos kaingang no Paraná à época das guerras de conquista que acirraram os conflitos e as cisões entre os grupos que rejeitaram e os que aderiram ao contato. Os estudos linguísticos de Wiesemann também forneceram uma indicação importante sobre a bacia hidrográfica como unidade territorial. Penso que hoje a maioria dos pesquisadores sobre os Kaingang adotou essa teoria.

Outro ponto que Wiesemann mostrou foi que as migrações se deram do norte para o sul. Os estudos de etnohistória de Becker (1976), Simonian (1981) e Mota (1994, 1998), mostraram que os grupos que se instalaram nos estados de Santa Catarina e Rio Grande do Sul eram provenientes do Paraná e que não aceitaram a política de aldeamento oferecida pelo governo provincial do Paraná. Portanto, os principais grupos kaingang que vivem hoje em SC e RS se expandiram a partir das fissões ocorridas na segunda metade do século XIX, portanto em época recente, confirmando os resultados do estudo de Wiesemann. 


\section{As pesquisas sobre territórios e territorialida-} des kaingang e suas lições

Minhas experiências de pesquisas somam aquelas realizadas na academia como exigência institucional, e também outras, provenientes de solicitações externas, seja na forma de perícias de terras ou de questões envolvendo crimes contra indígenas (assassinatos de brancos por indígenas ou vice-versa), de identificação étnica ou mesmo como testemunha de defesa em processos envolvendo índios.

Conheci os índios da região norte do Paraná durante os movimentos sociais que ocorreram em 1985/86 e em 1987 registrei meu primeiro projeto no CPG-UEL. Ao longo dos anos, várias demandas surgiram e desenvolvi projetos de extensão em um conjunto variado de atividades paralelas. Muitas ações sequer foram registradas porque a urgência das demandas não permitiu. Todos foram importantes para meu aprimoramento profissional e em muito contribuíram para aprofundar e detalhar aspectos da história e cultura tanto dos Kaingang quanto dos Guarani e Xetá. As pesquisas de campo incluíam as TIs Apucarana, Barão de Antonina, São Jerônimo (bacia do Tibagi), Laranjinha (bacia do Laranjinha) e Pinhalzinho (bacia do Cinzas) $)^{2}$. No final dos anos 1990 comecei uma pesquisa sobre os Kaingang e suas relações sobre o meio ambiente e estendi o campo até a TI Mococa. Como pesquisadora do LAEE na UEM, participei do Diagnóstico Etno-ambiental da Terra Indígena Ivaí-PR (Mota 2002) localizada na bacia do Ivaí e de outras atividades de pesquisa, ensino e extensão desenvolvidas pelo Laboratório ${ }^{3}$.

Com a divulgação dos projetos de construção de várias UHEs na bacia do Tibagi, registrei

2 As TIs Apucarana, Barão de Antonina e Mococa são habitadas por Kaingang; a TI São Jerônimo por Kaingang, Guarani e Xetá; as TIs Laranjinha e Pinhalzinho por Guarani.

3 A partir de 1996, com a divulgação do projeto de construção de várias UHEs na bacia do Tibagi, formou-se um movimento dos pesquisadores, principalmente da UEL e da UEM e de várias ONGs do Paraná denunciando os impactos sociais e ambientais da UHEs e o não cumprimento da legislação assim como a insuficiência dos estudos dos EIA-RIMA. um novo projeto de pesquisa na bacia do Tibagi focando as relações dos Kaingang com o meio ambiente e participei, juntamente com outros pesquisadores da UEL e da UEM na divulgação dos resultados das pesquisas sobre os impactos sociais e ambientais das UHEs junto ao MPF e instituições responsáveis pela fiscalização e acompanhamento dos processos de licenciamento (IBAMA; IAP) ${ }^{4}$.

Mesmo as intervenções de pequeno porte - como a identificação étnica, em agosto de 1994, de uma criança guarani cuja família vivia na periferia da cidade de Guaíra no Paraná - tiveram uma importância enorme. No caso específico da criança guarani, o laudo permitiu seu atendimento diferenciado no HU, e remeteu a uma realidade social mais complexa vivida pelos Guarani. Por meio daquela intervenção pontual, uma realidade até então despercebida entre nós, antropólogos, se revelou: vivam na periferia da cidade de Guaíra-PR, dezenas de famílias guarani que sobreviviam de trabalhos não qualificados nas olarias e outros serviços urbanos ou rurais. Os Guarani estavam reocupando territórios ancestrais ${ }^{5}$ e a cidade de Guaíra registrava três bairros novos habitados por dezenas famílias guarani.

Todas as experiências de antropologia aplicada foram enriquecedoras porque ampliaram minha visão sobre a complexidade e amplitude da questão indígena em todas as suas dimensões e me levaram para fora do âmbito das aldeias kaingang e guarani no Paraná e

4 Em março de 2002 enviamos o documento "Os Guarani na bacia do Paranapanema. Parentesco, casamento e redes de sociabilidade étnica" para o IBAMA com cópia para o MPF e IAP mostrando que os Guarani das bacias do Tibagi, Laranjinha e Cinzas formavam uma unidade sociológica e tinham direito à indenização caso qualquer barragem fosse construída. Da mesma maneira, outros pesquisadores da UEL e da UEM enviaram seus relatórios (Arqueologia, Etno-História, Biologia Animal e Vegetal, Química) para as mesmas instituições e todos foram importantíssimos para subsidiar as ações civis públicas impetradas pelo MPF.

5 Essa reocupação dos territórios tradicionais guarani continuou ocorrendo na região sudoeste do Paraná, de forma casa vez mais intensa, principalmente por causa do alagamento das terras guarani pela UHE Itaipu. 
Santa Catarina. Tanto a visita à família guarani em Guaíra quanto as perícias na aldeia urbana dos Kaingang na cidade de Chapecó-SC e dos Guarani de Araçaí nos municípios de Saudades e Cunha Porã-SC, mostraram-me que as territorialidades indigenas tinham extravasado as fronteiras oficiais, ou nunca haviam se restringido a elas. Para além das relações econômicas e de exploração do trabalho indígena, alianças vêm sendo costuradas através dos casamentos entre índios e brancos, na convivência promovida pela participação nas diferentes religiões, batizados, festas, bailes, futebol e outras. Essas constatações mostram que temos de romper a nossa tradicional delimitação do campo espacial e seguir os itinerários que os índios fazem nos interstícios da sociedade regional e estadual e no caso dos Guarani, transnacional.

\section{A realidade "vista de baixo" $\mathrm{X}$ a realidade "vista de cima"}

Como acima afirmado, ao longo das pesquisas e perícias realizadas no Paraná e Santa Catarina, fui ampliando meus conhecimentos a respeito da complexidade das realidades vividas pelos povos indígenas na atualidade. Fui descobrindo realidades do ponto de vista dos indígenas, isto é, "vistas de baixo para cima" e que difere em muito da realidade oficial, "vista de cima para baixo", esta instituída e reconhecida pelo Estado.

Nas pesquisas realizadas nas TIs na bacia do Tibagi pude mostrar, num relatório encaminhado ao IBAMA, MPF ${ }^{6}$ e outras instituições,

6 O relatório tinha por objetivo mostrar que os Guarani que viviam nas bacias do Tibagi, Laranjinha e Cinzas seriam impactados pela barragem de Mauá e teriam direitos à reparação tanto quanto os Kaingang. O laudo apresentado pelo empreendedor afirmava que apenas uma aldeia kaingang (TI Mococa) seria impactada. Nossas pesquisas subsidiaram a contestação dessa afirmativa e elaboramos estudos que foram encaminhados ao MPF mostrando que todas as aldeias kaingang e guarani que vivem nas 3 bacias seriam impactadas. Como resultado desse embate entre o MPF e o Consórcio empreendedor, houve a concordância que qualquer UHE construída na bacia do Tibagi, impactará todas as oito populações indígenas, Kaingang e Guarani que vivem nas bacias do Tibagi, Laranjinha e Cinzas. que os Kaingang tinham construído um território muito diferente e mais amplo que extrapolava os limites das TIs. Mais ainda, mostramos que os Kaingang e os Guarani que vivem nas bacias do Tibagi, Laranjinha e Cinzas formavam uma unidade interétnica construída desde que passaram a ser administrados pelos órgãos indigenistas oficiais que se sucederam no tempo desde o final do Império. Kaingang e Guarani das várias aldeias existentes nas TIs dessas bacias formam hoje uma intrincada rede de sociabilidade cujas famílias foram se vinculando por laços de consanguinidade e afinida$\mathrm{de}^{7}$ (Tommasino et al. 2002).

Nesse sentido, as pesquisas etnográficas mostraram aspectos desconhecidos e que não têm merecido atenção da academia. Não fosse o relatório que elaboramos para o IBAMA e demais órgãos, essa mestiçagem interétnica e a rede social de vínculos históricos entre TIs kaingang e guarani assim como com segmentos nacionais fora das TIs, continuariam invisíveis $^{8}$. Enfim, descobri que além da geografia e da história oficiais existem outras geografias e histórias que podemos descobrir olhando de baixo para cima.

A figura 1 mostra a realidade oficial que estamos chamando de realidade "vista de cima para baixo" e que nada mais é que aquela determinada pelo Estado, com limites fixos para os grupos locais kaingang e legitimados pelo sistema jurídico nacional. Para os povos indígenas, o espaço das TIs representou e representa espaços onde são vigiados e controlados, onde se localizam os equipamentos sociais como escola, posto de saúde, igreja, escritório da FUNAI local, salão de festa e outros. Desde os primeiros contatos e principalmente ao longo das décadas pós-conquista, esse espaço tornouse imprescindivel aos índios que passaram a

7 Seria importante uma pesquisa que pudesse apreender esse processo de alianças entre as diferentes etnias que tiveram de viver na mesma região e até mesmo na mesma TI. Na região Norte do Paraná, temos índios misturados mostrando alianças entre Kaingang, Guarani, Xetá, Fulni-ô e brancos.

8 Para a academia continua invisivel porque o relatório em questão foi muito pouco divulgado. 


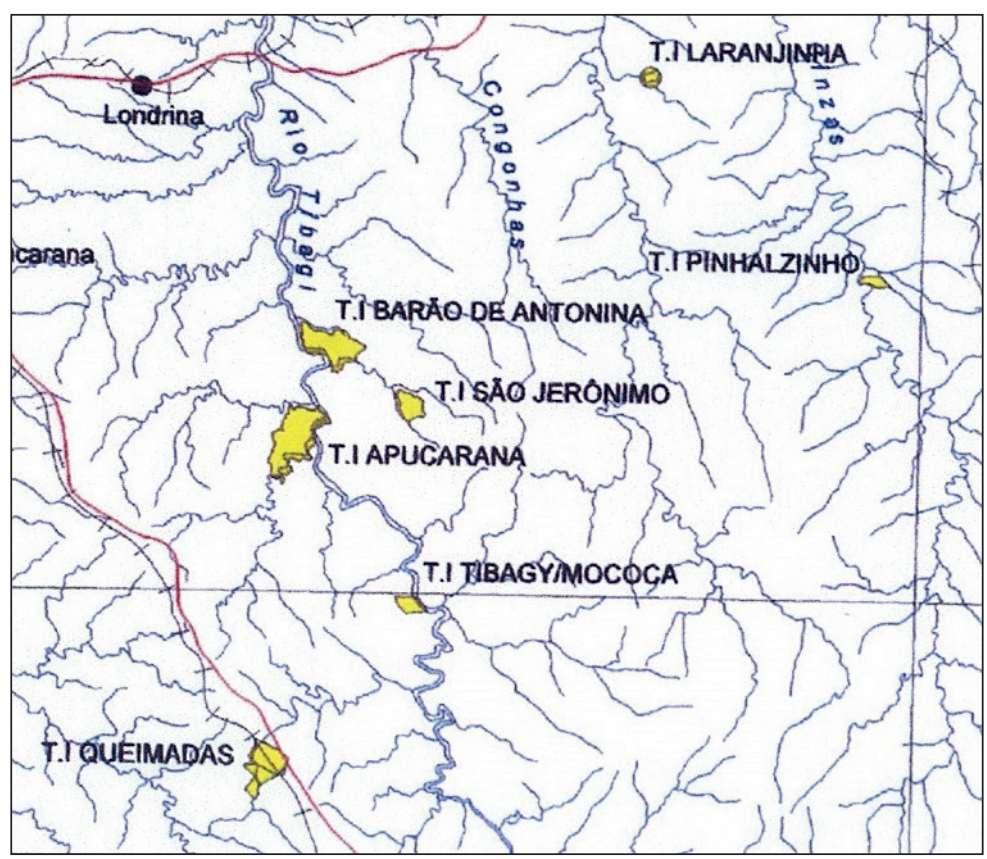

Fig. 1. Terras indígenas nas bacias do Tibagi, Laranjinha e Cinzas / Paraná. Realidade oficial, "vista de cima para baixo".

depender dos objetos industriais do mundo branco e com o esgotamento dos territórios de caça, pesca e coleta, tiveram de buscar outras alternativas de sobrevivência junto às estruturas do indigenismo ou mesmo por conta própria (Tommasino 1995).

Paradoxalmente, os espaços no interior das TIs também se tornaram, cada vez mais, espaços de liberdade porque é onde realizam seus rituais contemporâneos, onde caçam, pescam nos pari, fazem rodeios, bailes e jogam futebol. Mesmo tendo recebido casas de alvenaria do governo estadual, continuam a fazer diferentes tipos de ranchinhos (in xin) nos fundos ou ao lado das casas e ainda constroem em locais distantes do núcleo habitacional, ranchos tradicionais (inn), geralmente próximo às matas e aos rios. No inverno, permanecem semanas nos wãre (abrigo provisório) na beira dos rios quando armam os pari (armadilhas de pesca) nas corredeiras. Portanto, os espaços das TIs possuem essa duplicidade que é vivida cotidianamente, conforme eles se movem no tempo-espaço contemporâneo das TIs.
A figura 2 mostra a realidade "vista de baixo para cima”, isto é, do ponto de vista dos índios. Como vimos, os Kaingang tiveram de buscar trabalho para comprar os produtos de mercado que se tornaram itens indispensáveis de sua dieta assim como roupas, sapatos e outros produtos. Cada vez mais fazem parte do mercado consumidor e para isso têm de se submeter aos serviços que são ofertados em cada momento. Ao longo do século XX as famílias chegaram a trabalhar em fazendas do Paraná e do Estado de São Paulo onde formaram colônias (Krug 1913). Conheci índios kaingang e guarani que disseram ter trabalhado nos sítios de vários municípios mais ou menos próximos das aldeias, sendo que algumas famílias moraram durante décadas em locais fora das terras delimitadas, em locais de difícil acesso, fora das terras delimitadas onde permaneceram até os anos de 1980.

No passado mais recente, nos anos de 1990, os homens das TIs São Jerônimo, Barão de Antonina e Apucarana foram cortar cana no Mato Grosso do Sul, nas usinas de açúcar e álcool (Tommasino 1995). Hoje cortam e carregam 
troncos de eucaliptos das fazendas da região que são vendidos para a Klabin ${ }^{9}$. Por outro lado, as pesquisas mostraram que os Kaingang, mesmo depois das terras dos antigos Postos Indígenas terem sido reduzidas nos anos $1945^{10}$ e $1951^{11}$, muitas famílias continuaram morando fora desses perímetros e mantiveram suas armadilhas de pesca nas corredeiras de vários rios em cujas margens tinham moradia fixa (in) ou construíam abrigos provisórios (wãre). Com o cercamento das fazendas, muitos fazendeiros passaram a impedir que os índios mantivessem ativas as armadilhas de pesca conhecidas como pari. Isso

9 Fábrica de papel localizado em Telêmaco Borba-PR.

10 Decreto lei 7.692 de junho de 1945.

11 Decreto 13.722 de 19/01/1951 que legitimou o Acordo de 1949 entre os governos do Paraná e da União. Esses dois decretos mostram que o próprio Estado praticou os maiores esbulhos de terra dos povos indígenas no Paraná. ocorreu entre as décadas 1960 e 80, dependendo da região (Tommasino 1995, 1998).

Outra forma de obter recursos para a compra de mantimentos, roupas e sapatos foi o surgimento da cestaria mercantil que as mulheres passaram a fazer e vender nas cidades. Para isso, as artesãs passaram a frequentar as cidades cada vez mais intensamente. Praticamente todas as cidades norte-paranaenses são frequentadas pelas famílias kaingang e nas épocas que antecedem as festas contemporâneas, há uma espécie de inchamento das cidades porque todos querem comprar roupas novas e precisam de muita comida e bebida para receber os parentes de outras aldeias que virão.

A figura 2, obviamente será sempre incompleta e provisória porque a territorialidade kaingang não possui fronteiras fixas e está sempre em movimento de expansão ou retração. O objetivo principal é mostrar que a realidade vivida concretamente pelos índios possui outras

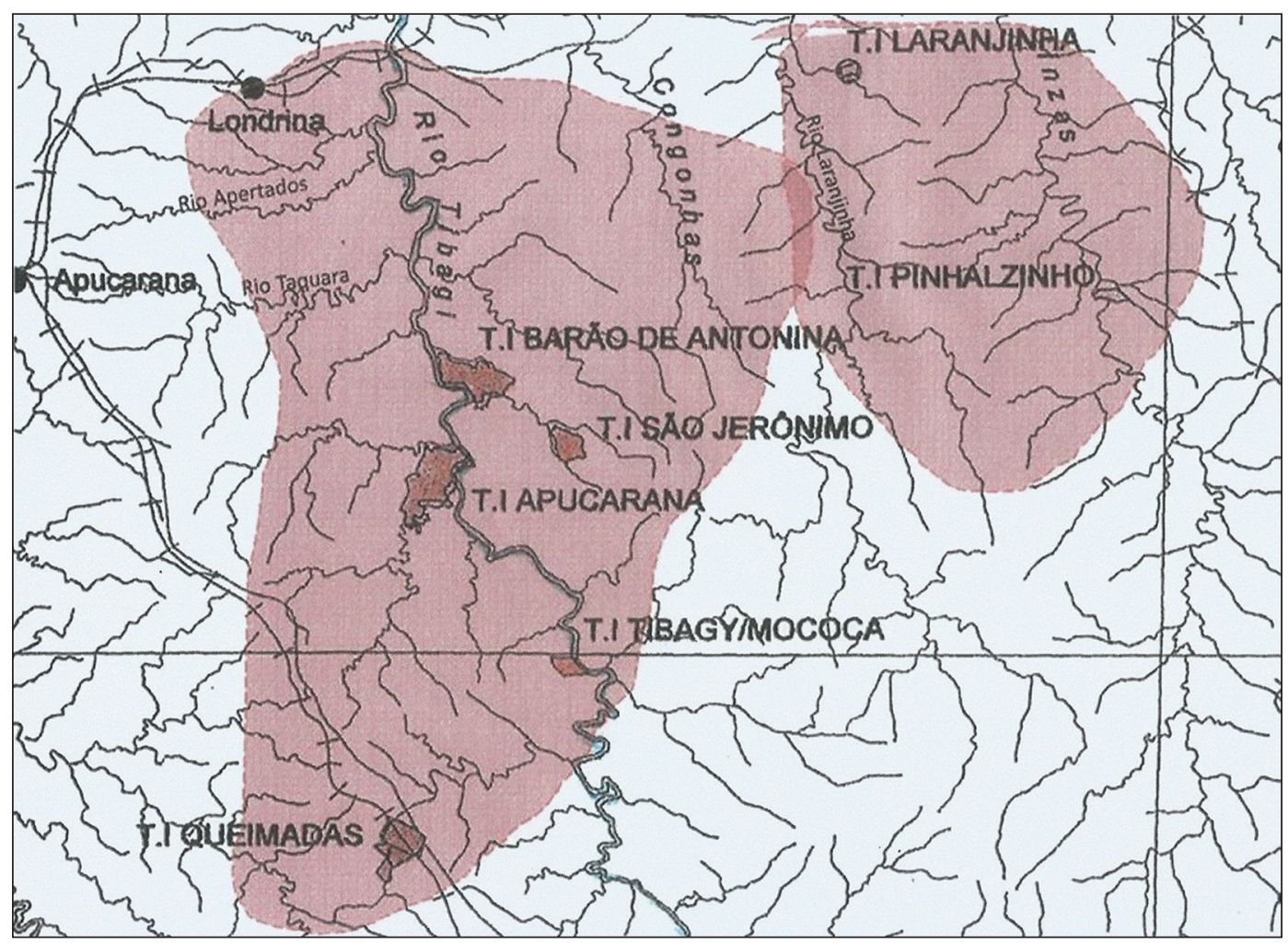

Fig. 2. Territórios e territorialidades Kaingang. Bacia do Paranapanema, séculos XIX - XXI. Realidade vista de baixo para cima. 
Reflexões sobre a territorialidade Kaingang e a importância da inter-trans-disciplinaridade

R. Museu Arq. Etn., 27: 121-134, 2016

cartografias que não coincidem com aquelas definidas pelo Estado. Quando falamos em exercício de sua territorialidade é preciso alguns esclarecimentos. Em primeiro lugar, não significa que os Kaingang retomaram as terras de seus antepassados nem que todos os locais visitados se tornaram parte de seus territórios. Trata-se de uma territorialização espacial e social construída relacionalmente com outros coletivos, habitantes de cada região. Os índios dependem do comércio local para abastecimento em geral, vendem o excedente dos produtos da roça na cidade, construíram relações de compadrio e de afinidade com os brancos regionais, participam de rodeios, jogos de futebol, bailes e festas religiosas. Alguns índios são católicos, outros pentecostais ou evangélicos. Enfim, os índios estão inseridos numa rede social mais ampla que muitas vezes as pesquisas não mostram porque o campo de pesquisa fica quase sempre restrito aos espaços das aldeias, dentro dos limites das TIs. Soma-se a isso o fato de que na academia, quando se estuda as relações dos índios com a sociedade envolvente, quase sempre são ressaltadas as relações de dominação, de exploração e de exclusão. O que aparece nessas pesquisas é apenas uma parte da realidade. Em todas as minhas pesquisas pude observar uma diversidade de formas de interação interétnica: de conflito, exploração, exclusão, assim como de consenso, adesão e inclusão.

Quando acompanhei o movimento social de expulsão dos posseiros da TI Barão de Antonina, um fato me causou espanto: havia tanto tempo que os Kaingang conviviam com os posseiros brancos que muitos tinham se casado com mulheres kaingang e havia um número considerável de filhos mestiços, alguns vivendo nas aldeias da TI e outros vinculados às famílias de posseiros. O que se observa é que os Kaingang fazem parte da sociedade local, de forma efetiva, participam de uma rede de sociabilidade ampla e diversificada, de ordem socioeconômica, religiosa, política, historicamente construída ao longo de quase dois séculos. Nesse sentido, é fundamental que as análises históricas sejam acompanhadas da análise da geografia kaingang e ainda contrapondo-se à história e à geografia da sociedade dominante. Assim teremos condições de dar visibilidade tanto à história e geografia "vista de baixo para cima" como as "vistas de cima para baixo”. São histórias cujas territorialidades se superpõem, se interpenetram, se influenciam e se contrapõem.

Na pesquisa de Mota e Novak acima referida, os autores partiram dos dados arqueológicos que comprovam a presença dos povos indígenas no Paraná e, a partir de registros históricos, foram mostrando como esses territórios foram sendo expropriados e ocupados pelos europeus e seus descendentes num processo que começou no século XVI até os dias atuais. Adotaram a realidade do ponto de vista dos povos indígenas, isto é, mostraram a realidade "de baixo para cima”. Os autores mostraram como a sociedade paranaense foi sendo construída a partir dos processos de desterritoriazação das populações indígenas na bacia do Ivaí até 1949, quando um Acordo entre a União e o Estado do Paraná executou uma redução drástica das áreas indígenas, legitimado pelo Decreto 13.722, de 19 de janeiro de 1951 .

\section{As várias camadas da cidade de Chapecó-SC}

O laudo de identificação mostrou que as famílias da aldeia Kondá na cidade de Chapecó-SC, tinham um histórico vinculado com a constituição das TIs pelos governos imperial e republicano que, por sua vez, foram se desdobrando em processos internos de conflito, disputa de poder, expulsões, castigos cruéis e outras formas de discriminação e violência. As condições chegaram ao limite do suportável para algumas famílias que não tiveram outra alternativa a não ser saírem das TIs e viverem acampados nas periferias das cidades, vendendo seus artesanatos ou trabalhando em serviços braçais na cidade ou na zona rural. Foram surgindo então famílias que a instituição tutelar denominava "desaldeadas", vivendo precariamente em abrigos de lona ou construídos com restos de madeira e papelão, muitas vezes colocando seus filhos a mendigar. Os Kaingang da aldeia Kondá afirmaram categoricamente que não desejavam voltar para as TIs 
de origem, mas sim transferir a aldeia para a zona rural, onde pudessem viver melhor, sem os perigos da cidade. A pesquisa revelou que a sede do município de Chapecó foi construída sobre o território tribal dos antepassados das famílias que viviam na aldeia Kondá.

A figura 3 busca mostrar que a história de Chapecó foi construída em camadas. Anteriormente havia uma comunidade kaingang que vivia na área onde hoje é a cidade: a nossa equipe, junto com os anciões da aldeia, identificou os locais aproximados onde tinham a aldeia (emã), os cemitérios, os locais de coleta, além das outras aldeias que existiam na região.

Demonstramos que a situação histórica integrou no mesmo campo político, diferentes grupos étnicos indígenas com europeus de diferentes etnias em momentos diferentes da história recente e foi responsável pelo cruzamento/ confronto, contradição/consenso, identidade/ alteridade e múltiplas territorialidades que perpassaram as relações sociais das fronteiras étnicas e sociais (Tommasino et al. 1998: 107).

Identificou-se a existência de dois outros grupos de famílias kaingang que viviam na cidade de Chapecó inseridos no mercado de trabalho não qualificado, habitando bairros da periferia, sem contato com a FUNAI. Esse olhar mais amplo, permitiu visualizar, para além das especificidades de cada um dos três grupos pesquisados na cidade, a estruturação de uma rede social que preservava os mesmos princípios estruturadores da territorialidade kaingang: ao local de residência fixa - a cidade - agregavam-se dezenas de outros locais (morada dos parentes, locais de venda de artesanato, centros religiosos, etc.), revelando o amplo espaço de mobilidade e (re)territorialização dos Kaingang (Tommasino et al. 1998: 127).

Os gráficos de parentesco mostraram que as famílias da Aldeia Kondá estavam vinculadas por laços de parentesco e de afinidade com várias TIs. Essa rede de sociabilidade entre TIs e com famílias kaingang que vivem fora das TIs revelaram a existência desse território social kaingang, invisivel até então, não como relação abstrata, mas como realidade social concreta produzida e vivida ao longo da história recente, nos interstícios do sistema dominante (Tommasino et al. 1999: 23).

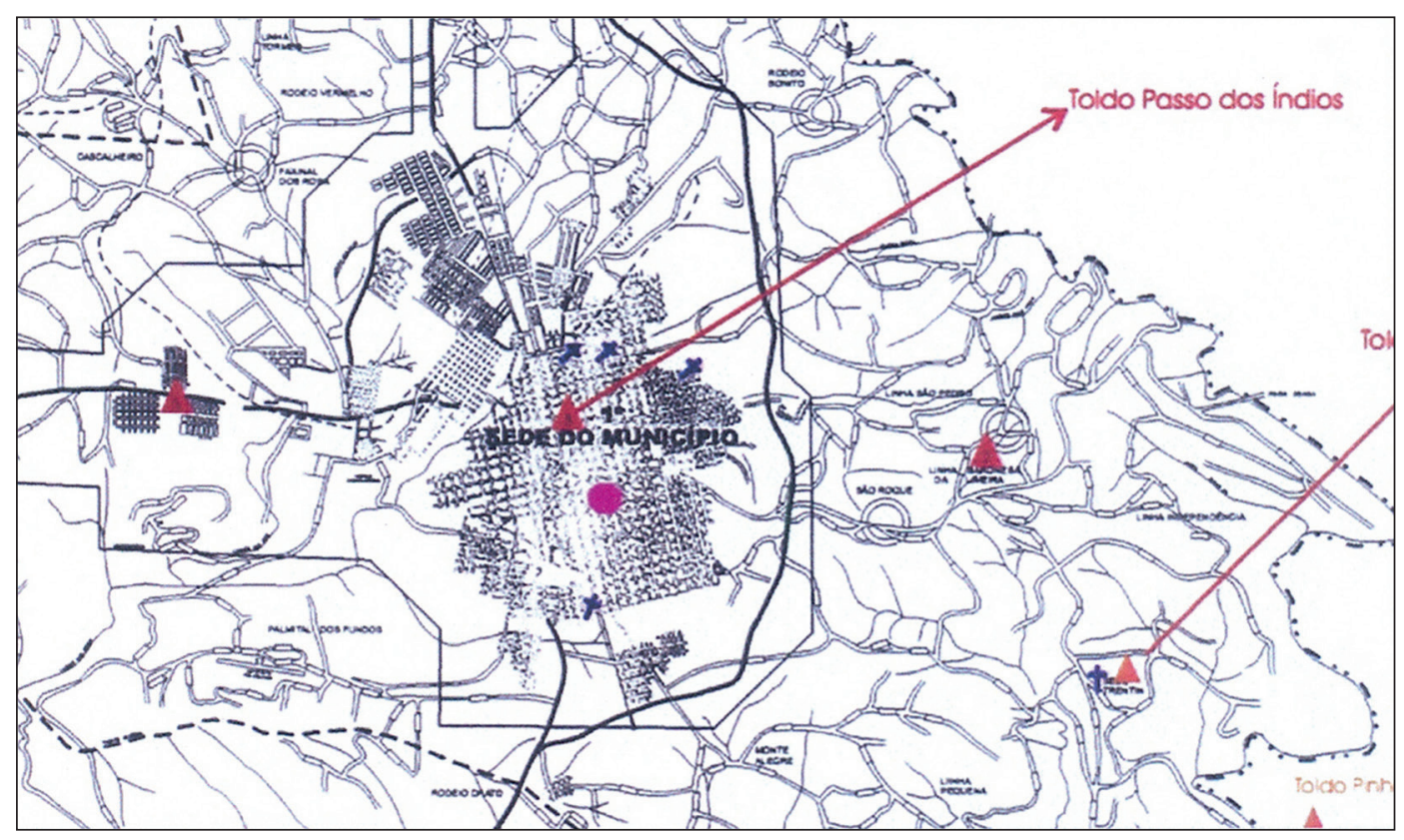

Fig. 3. Chapecó surgiu sobre a terra tradicional dos antepassados dos Kaingang da aldeia Kondá (as camadas de Chapecó). Locais de toldos antigos (final do século XIX - início do século XX). 


\section{Temas importantes não têm merecido estudos na academia}

Ao longo de quase trinta anos de experiência em pesquisa com populações indígenas, de pesquisa acadêmica e antropologia aplicada, identifiquei várias áreas ou temas relacionados aos índios que não têm recebido atenção dos pesquisadores.

Vimos que os índios romperam as fronteiras delimitadas pelo Estado e se territorializaram para muito além das TIs e os intercasamentos sempre aconteceram desde os primeiros contatos. Quando Lévi-Strauss viajou pelo norte do Paraná e visitou os Kaingang, deixou registrado que em seu percurso para chegar à reserva de São Jerônimo em 1935, levou cerca de quinze dias a cavalo ${ }^{12}$. Ele descreve uma das paragens antes de chegar à aldeia dos índios:

Em breve, um som se torna mais nítido ao longe. Já não é o rugido do jaguar, que ouvimos durante um momento no crepúsculo. Desta vez é um cão que está a ladrar: a paragem está perto. Alguns minutos mais tarde o nosso guia muda de direção; penetramos atrás dele num pequeno baldio onde uma barreira de troncos cortados delimita um cercado para gado; diante de uma choça, feita de palmeiras intervaladas, sobrepujadas por um teto de palha, movem-se duas figuras que envergam uma ligeira roupagem de algodão branco: os nossos anfitriões, o marido muitas vezes de origem portuguesa, a mulher índia" (Lévi-Strauss 1955: 197-198; grifo meu).

\section{Com a intensificação da colonização nas} décadas de 1940 em diante, as populações indígenas se viram envolvidas cada vez mais em contato forçado com os colonizadores que foram se instalando em todas as direções. Fazendas e cidades surgiram sobre seus territórios de caça e coleta e até mesmo sobre seus cemitérios ${ }^{13}$.

12 Lévi-Strauss não diz de onde saiu, mas acredito que seria de Londrina, a cidade mais importante naquela época e sede da Companhia de Terras Norte do Paraná.

13 A cidade de São Jerônimo da Serra-PR foi construída, segundo me disseram, sobre dois cemitérios kaingang, pois que eles consideram um sendo dos mortos Kamé e outro dos Kairu.
Outro ponto que gostaria de salientar é que as pesquisas, quando focam os Kaingang, os demais sujeitos desaparecem ou aparecem como Outros genéricos, abstratos, sem cultura própria. No caso da história kaingang, muito antes da conquista, os Kaingang já conheciam os Guarani e outras etnias e suas histórias se cruzavam (no passado, como inimigos principalmente) e continuaram até os dias atuais. São poucas ainda as pesquisas sobre relações interétnicas no Paraná, mas podemos citar Pires (1975), Tommasino (1995), Mota (1994; 1998) e Mota \& Novak (2008).

Essas pesquisas mostraram a importância da integração entre Antropologia ${ }^{14}$, História e Geografia. O importante é que o resultado mostra a sociedade kaingang com suas especificidades socioculturais em sua dinâmica no tempo e no espaço, como um entre vários sujeitos da história paranaense.

Seria desejável incrementar mais pesquisas sobre relações interétnicas e interculturais e que pudessem mostrar a diversidade também dos brancos com suas especificidades - italianos, alemães, japoneses, negros ( $k$ a pũr), gaúchos, paulistas, mineiros - assim os Outros aparecerão como sujeitos de uma história multiétnica e multicultural $^{15}$ nos espaços geográficos correspondentes e os textos serão polissêmicos, dialógicos e policentrados. Nesses estudos a integração dos conhecimentos da Arqueologia, da História, da Linguística, da Geografia e outras disciplinas permitirão revelar as diferentes camadas da história e as várias realidades "vistas de baixo para cima”.

14 Estou considerando que a análise antropológica inclui a análise sociológica e política, portanto, forma uma totalidade.

15 Conheci um guarani na TI São Jerônimo que trabalhou na juventude numa propriedade rural de uma família japonesa na região de Assaí, numa época em que as relações de trabalho implicava na permanência do trabalhador na propriedade. Com isso ele aprendeu a falar fluentemente a língua japonesa. Da mesma forma, outros índios das TIs da região norte do Paraná mantêm relações amistosas com as famílias de origem japonesa, nas cidades e distritos próximos às aldeias. Na região sudoeste, sabemos que os índios mantêm relações sociais com os descendentes de poloneses, alemães e italianos. Mas até agora não temos pesquisas específicas sobre essa realidade. 


\section{Considerações finais}

Neste breve ensaio sobre a produção antropológica sobre os Kaingang vimos o quanto é importante a inter-trans-disciplinaridade como estratégia para superar as limitações da fragmentação disciplinar própria do paradigma cartesiano. Este recurso vem possibilitando a troca e a integração de conhecimentos que permitem mostrar a complexidade das realidades vividas pelos indígenas num contexto histórico onde diferentes fatores e sujeitos interagem constantemente.

Na segunda metade do século XIX os Kaingang vivenciaram novas experiências que mudaram para sempre suas vidas. De povos livres e independentes tornaram-se parte de uma nova ordem onde foram compulsoriamente inseridos na condição de povos conquistados. No novo contexto histórico, os Kaingang mantiveram seus sistemas culturais, mas para isso, tiveram de se reinventar inúmeras vezes para garantir sua sobrevivência. Nesse sentido mostramos a coexistência de duas realidades que se sobrepõem e se contrapõem: a "realidade vista de cima para baixo" (a oficial) e a "realidade vista de baixo para cima” (a do ponto de vista kaingang). Apontamos algumas pesquisas que vêm sendo produzidas em várias instituições acadêmicas e estão rompendo as barreiras disciplinares.

Ainda falamos de aspectos pouco aprofundados da realidade indígena, por não serem objetos de pesquisa específica ou por se localizarem fora do campo espacial delimitado das pesquisas antropológicas: estudo das relações interétnicas, de mestiçagem e de interculturalidade. Reafirmo a importância de se estudar os fenômenos da mestiçagem e dos processos interculturais em áreas de convivência de grupos étnicos diversos. Numa ocasião, em visita informal às aldeias da TI Barão de Antonina, um grupo de mestiços deixou registrado o sentimento de excluídos pela academia com um sonoro "mas nós existimos!".

TOMMASINO, $\mathrm{K}$. Thinking about Kaingang territoriality and the role of inter-transdisciplinarity. R. Museu Arq. Etn., 27: 121-134, 2016.

Abstract: This article aims - from many researches and extension experiences with Kaingang - point out some considerations about the limitations of the Cartesian paradigm still prevails in Universities and show that one way to overcome them is to adopt (trans and inter) disciplinary approach. I try to show that this feature allows you to advance in the analysis of the complexity of the realities experienced by Kaingang throughout recent history. For this I cut out the research on Kaingang territories and territoriality in Parana and Santa Catarina. Finally, I try to show that there are still important aspects of socio-cultural and historical reality of these people who have been not the subject of specific research.

Keywords: Kaingang; Interdisciplinarity; Anthropology; Territoriality. 


\section{Referências Bibliográficas}

Baldus, H. 1979. Ensaios de Etnologia Brasileira. São Paulo: INL/MEC

Becker, I. 1976. O Índio Kaingang do Rio Grande do Sul. Instituto Anchietano de Pesquisas/ Unisinos. São Leopoldo.

Morin, E. 2002. Educação e complexidade: os sete saberes e outros ensaios. Almeida, M.C., Carvalho, E.A. (Orgs.) - São Paulo: Cortez.

Mota, L.T. As guerras dos indios Kaingang: A história épica dos índios Kaingang no Paraná. Maringá: EDUEM, 1994.

Mota, L.T. 1998. O aço, a cruz e a terra: índios e brancos no Paraná provincial (1853-1889). Tese de doutoramento em História, UNESP-Assis.

Mota, L.T. 2002. (Org.). Diagnóstico Etno-ambiental da Terra Indigena Indígena Ivai-PR. Programa Interdisciplinar de Estudos de Populações. Maringá: Laboratório de Arqueologia, Etnologia e Etno-História/ UEM.

Mota, L.T.; Novak, E.S. 2008. Os Kaingang do Vale do Rio Ivai-PR: história e relações interculturais. EDUEM. Maringá.

Nimuendaju, C. 1993 [1913]. Etnografia e Indigenismo: sobre os Kaingáng, os Ofaié-Xavante e os Índios do Pará. Editora da UNICAMP. Campinas.

Pires, M.L.M. 1975. Guarani e Kaingang no Paraná: um estudo de relações intertribais.
Dissertação de mestrado em Antropologia da UNB. Brasília.

Schaden, E. 1959. A Mitologia heróica de tribos indígenas do Brasil. Departamento de Imprensa Nacional. Rio de Janeiro.

Simonian, L.T.L. 1981. Terra de posseiro: um estudo sobre as politicas de terras indígenas. Dissertação de mestrado. UFRJ/Museu Nacional.

Tommasino, K. 1995. A História dos Kaingang da Bacia do Tibagi: uma sociedade Jê Meridional em movimento. Tese de doutoramento em Antropologia da USP. São Paulo.

Tommasino, K.; Cabral Jr., V.A. ; Capucci, J. 1998. Identificação das famílias kaingang residentes na cidade de Chapecó. FUNAI-DAF/ MJ, Brasília. Datilografado.

Tommasino, K.; Capucci, J.M.R. e Cabral Jr., V.A. Eleição de área para os Kaingang da Aldeia Kondá. Relatório II. FUNAI/MJ. Chapecó, agosto de 1999.

Tommasino, K.; Barros, V.E.N. e Quinteiro, C.T. Março de 2000. Os Guarani na bacia do Paranapanema. Parentesco, casamento e redes de sociabilidade étnica. Relatório Complementar e Preliminar Especialmente Elaborado para o IBAMA/Comissão de Licenciamento da UHE São Jerônimo. Londrina.

Wiesemann, U. 1978. Os dialetos da língua Kaingáng e Xokléng. Arquivos de Anatomia e Antropologia, 3: 197-217. 